\title{
Cost analysis of critical patient care at a pediatric intensive care unit of a tertiary care public hospital in an urban metropolis of India
}

\author{
Renuka P. Munshi ${ }^{1 *}$, Alisha Dhiman ${ }^{1}$, Sushma U. Save ${ }^{2}$
}

\begin{abstract}
${ }^{1}$ Department of Clinical Pharmacology, ${ }^{2}$ Department of Pediatrics, TN Medical College and BYL Nair Hospital, Mumbai, Maharashtra, India
\end{abstract}

Received: 24 May 2021

Accepted: 16 June 2021

\section{*Correspondence:}

Dr. Renuka P. Munshi,

Email: renuka.munshi@gmail.com

Copyright: (C) the author(s), publisher and licensee Medip Academy. This is an open-access article distributed under the terms of the Creative Commons Attribution Non-Commercial License, which permits unrestricted non-commercial use, distribution, and reproduction in any medium, provided the original work is properly cited.

\begin{abstract}
Background: The cost of critical care is widely recognized as being high. However, it remains a challenge to accurately assess the cost of intensive care due to a lack of standardized methodology. There is also considerable heterogeneity with regard to allocation of resources and distribution of critical care services.

Methods: We conducted a prospective study to analyse diagnosis-based costs of paediatric patient care at a pediatric intensive care unit (PICU) in a public hospital in Mumbai on the basis of identified cost components; direct (fixed and variable) and indirect costs.

Results: Out of 167 (102 boys, 61\%) patients enrolled, 65 (39\%) were aged 1-7 months. They spent an average of $4 \pm 1.46$ bed days in the PICU. The cost of direct fixed components (salaries, capital equipment, disposables) was Rs. $64,48,200$ for six months. The maximum cost of direct variable components spent by the hospital (physiotherapy intervention, expert opinion, investigations, medicines, blood products, piped gases) amounted to Rs. 548.63/patient/day for treatment of non-infectious diseases. Cost of indirect components (building maintenance) was Rs. 12,500/six months. Linear regression analysis showed 83-99.99\% dependency of treatment cost to diagnosis and bed days. The average cost of treatment of infectious and non-infectious diagnoses/patient/day spent by the hospital was Rs. 260 and Rs. 548.63 respectively as compared to Rs. 169.96 and Rs. 356.21 spent by the patients.

Conclusions: Our study showed that majority of the treatment costs depended on the diagnosis and number of bed days of the patients. Also being a tertiary care public hospital, $60 \%$ of the treatment costs were borne by the hospital. Thus, our study attempts to quantify, in financial terms, the expenditure involved in running a paediatric ICU in a tertiary care public hospital so as to assist doctors and healthcare decision makers in the allocation of resources.
\end{abstract}

Keywords: Critical patient care, Pediatric intensive care unit, Costs, Direct fixed components, Direct variable components, Indirect components, Public hospital

\section{INTRODUCTION}

Improvement in healthcare has resulted in an increase in life expectancy. However, these scientific and technological advances have come at a cost to patients and the health care system which has made the role of economic evaluation of healthcare interventions increasingly important. ${ }^{1}$ In addition, the central and various state governments have launched various welfare schemes to ensure that the disadvantaged sections of the society also receive quality care. Many of these schemes require payments to be made to the providers on the basis of estimated costs with a provision for reasonable profit. Hence, performing cost analysis studies at regular intervals has become extremely important for the economic evaluation of health-care interventions.

The concept of critical care management in India is only a few decades old however it is widely recognized as being 
expensive. ${ }^{2,3}$ Lack of a standardized methodology for calculating costs, makes estimation of costs of critical care services a challenging job. Also, there is considerable heterogeneity within the country in allocation of resources and distribution of critical care services making the inverse care law highly applicable in India, whereby those with the greatest need for health care have the greatest difficulty in accessing health services and are least likely to have their health needs met. This can only be improved by carrying out extensive and elaborate cost analysis studies.,

The cost of critical care would depend on the country, patient/ disease profile, level of technology employed in care amongst others. Hence, while the cost of care per day per patient was estimated to be $\$ 1,508 \pm 475$ (1992 Canadian dollars) in a Canadian ICU in 1996, the same was estimated in the Indian setting to be a meagre Rs. 2238 (equivalent to $\$ 43.20$ Canadian Dollars) in 2016. ${ }^{6,7}$ Although, a part of the difference could be due to differences in the methodology employed in the estimation, it cannot be the only reason. India is a vast country of great diversity and healthcare facilities across the country differ as per the healthcare needs of the people and hence, studies from different regions and areas would be required to be carried out to get a truer picture.

Pediatric intensive care units (PICUs) are an essential part of any children hospitals and contribute significantly in providing health care to children. ${ }^{8}$ As with other ICUs, they consume a lot of resources and are considered to be expensive. However, as the patient profile of those admitted in PICUs and the kind of care to be provided are quite different from those in the adult ICUs; one cannot make an estimation of cost of PICU care by extrapolation of results obtained from adult ICUs. ${ }^{9}$ In addition, the cost determinations need to be carried out periodically as new (costly) technologies are employed and newer drugs are prescribed. On reviewing studies published in the last 5 years, we found that there are few reports in Indian literature that have described health care costs in adult ICU and neonatal ICU care, but there is hardly any comparable literature regarding healthcare costs of PICU. ${ }^{12,13}$ This study was hence undertaken to assess the direct and indirect cost of treatment in the pediatric ICU of a public tertiary care hospital. ${ }^{10,11}$

\section{METHODS}

This prospective, observational study was carried out over a period of 7 months (from $1^{\text {st }}$ June 2013 to $31^{\text {st }}$ December 2013) after obtaining approval from the Institutional Ethics Committee (IEC) [ECARP project no. ECARP/2013/61 dated 22 nd August 2013]. The IEC provided a waiver of consent. The study enrolled consecutive patients of either sex aged between 1 month and 12 years of age (both inclusive) admitted in the 7 bedded PICU of a tertiary care public hospital in Mumbai, India. Only those patients who were admitted in the PICU for at least 24 hours were included. Data collected included information like demographic details, monthly family income, diagnosis, number of bed days in the PICU, daywise drugs prescribed, investigations carried out and blood and blood products transfused.

Post data collection the cost components were assessed using the 'bottom up' approach wherein, there is a detailed assignment of costs to individual patients according to their use of resources and unit costs of factors such as drugs, consumables and clinical support services. The cost components were identified as direct and indirect costs; direct cost included fixed and variable costs.

Direct fixed cost components included: salaries of the clinical and support staff such as senior medical faculty, medical residents, nursing staff, ward boys and helpers (class IV) working in the PICU; total cost of disposables consumed over the study period and; assets such including equipment and machinery used in the PICU that were expected to be functional for at least 1 year. The fixed cost of the equipment was costed based on the recommendations in section 179, modified accelerated cost recovery system (MACRS) to calculate yearly depreciation of products and properties including medical equipment as $10,18,14.40,11.52,9.22,7.37,6.55,6.55$, $6.56,6.55$, and 3.28 percent for years 1 through 10 , respectively. ${ }^{14}$

Direct variable cost included physiotherapy intervention and expert consultations (e.g. cardiology and neurology) for individual patients which were calculated using a standard unit of time, investigations including radiology, haematological, biochemical and microbiological tests which were recorded per patient per day, costs of blood, blood products and piped gases and costs of medicines prescribed per patient. Direct variable costs differed from patient to patient depending on the diagnosis and the number of bed days in the PICU.

Indirect cost component included the depreciation and maintenance costs of the PICU (infrastructure and equipment) which was obtained from the engineering department of the hospital.

\section{Statistical analysis}

Descriptive statistical analysis was used for the cost analysis and to compare treatment costs that were borne by the hospital and the patients respectively. The costs were calculated on the basis of direct and indirect cost components. Linear regression was applied taking average number of bed days as independent variable and the average cost as the variable dependent upon the number of bed days where diagnosis was that factor on which the variables were dependent.

Relationships among the dependent variables and the independent variables were statistically described by means of regression analysis. Regression was calculated with the help of GraphPad InStat 3 software. 


\section{RESULTS}

Of the 197 patients were admitted in the PICU during the study period, 167 patients fulfilling the eligibility criteria were enrolled in the study out of which $61 \%$ were boys. Out of the total study population, $38.92 \%$ of the patients were between the age group of 1 to 7 months with mean age being 3 years 3 months (interquartile range: 1 month to 12 years). $59 \%$ of the study population had a monthly family income between Rs. 5000-10000. The demographic details and income status has been summarised in Table 1.

Table 2 provides details of the various ailments from infectious and non-infectious causes affecting the different body systems such as the central nervous system, respiratory system etc. while Table 3 summarises the number of bed days occupied by the patients suffering from these ailments, which ranged from 3 days for most infectious diseases and also infectious disorders except those affecting the musculoskeletal system wherein the number of days the patients were admitted went as high as 42 days.

The cost of direct fixed components (salaries, capital equipment and disposables) and direct variable components (physiotherapy intervention, expert consultation, laboratory investigations, medicines, blood products, piped gases) was calculated to amount to Rs. $80,65,608.00$ while the Indirect cost was calculated to be Rs. 63,33,032 (Table 3).

Table 1: Demographic details of patients enrolled in the study.

\begin{tabular}{|c|c|}
\hline Parameter & Frequency $(n=167)$ \\
\hline \multicolumn{2}{|l|}{ Age } \\
\hline $1-7$ months & $65(38.92)$ \\
\hline 7 months 1 day- 11 months & $13(7.78)$ \\
\hline 11 months 1 day -3 years & $27(16.16)$ \\
\hline 3 years 1 month-7 years & $33(19.76)$ \\
\hline 7 years 1 month- 12 years & $29(17.36)$ \\
\hline \multicolumn{2}{|l|}{ Gender } \\
\hline Male & $102(61)$ \\
\hline Female & $65(39)$ \\
\hline \multicolumn{2}{|l|}{ Family income per month (INR) } \\
\hline Up to 5000 & $54(32.33)$ \\
\hline$>5000-10000$ & $99(59.28)$ \\
\hline$>10000$ & $14(8.38)$ \\
\hline Infections of the respiratory system & $20(11.97)$ \\
\hline Non-infectious diseases of the respiratory system & $17(10.17)$ \\
\hline Infections affecting the blood-stream or multiple systems & $17(10.17)$ \\
\hline Non-infectious diseases affecting the blood-stream or multiple systems & $15(8.98)$ \\
\hline Infections affecting the central nervous system & $12(7.18)$ \\
\hline Non-infectious afflictions of the central nervous system & $28(16.76)$ \\
\hline Non-infectious diseases of the cardio-vascular system & $19(11.37)$ \\
\hline Non-infectious diseases of the urinary system & $5(2.99)$ \\
\hline Infections affecting multiple systems & $17(10.17)$ \\
\hline Non-infectious diseases affecting multiple systems & $15(8.98)$ \\
\hline Infections affecting musculoskeletal system & $3(1.79)$ \\
\hline Non-infectious diseases affecting the musculoskeletal system & $1(0.59)$ \\
\hline Pyrexia of unknown origin (PUO) & $20(11.97)$ \\
\hline
\end{tabular}

Table 2: Average number of bed days according to diagnosis.

\begin{tabular}{|llll|}
\hline Diagnosis & Infectious (days) & Non-infectious (days) & $\begin{array}{l}\text { Pyrexia of unknown } \\
\text { origin (PUO) (days) }\end{array}$ \\
\hline Cardiovascular system & - & $4 \pm 1.14$ & - \\
\hline Multiple system involvement & $3.7 \pm 2.17$ & $3.5 \pm 2.11$ & $4 \pm 1.81$ \\
\hline Musculoskeletal system & $3.6 \pm 1.99$ & 41.69 & - \\
\hline Nervous system & $3.7 \pm 2.10$ & $3.6 \pm 2.31$ & - \\
\hline Respiratory system & 3.51 .97 & $3.7 \pm 2.88$ & - \\
\hline Urinary system & - & $4.4 \pm 1.11$ & - \\
\hline Fever & $4 \pm 1.27$ & - & $3.6 \pm 2.98$ \\
\hline
\end{tabular}


Table 3: Direct and indirect costs.

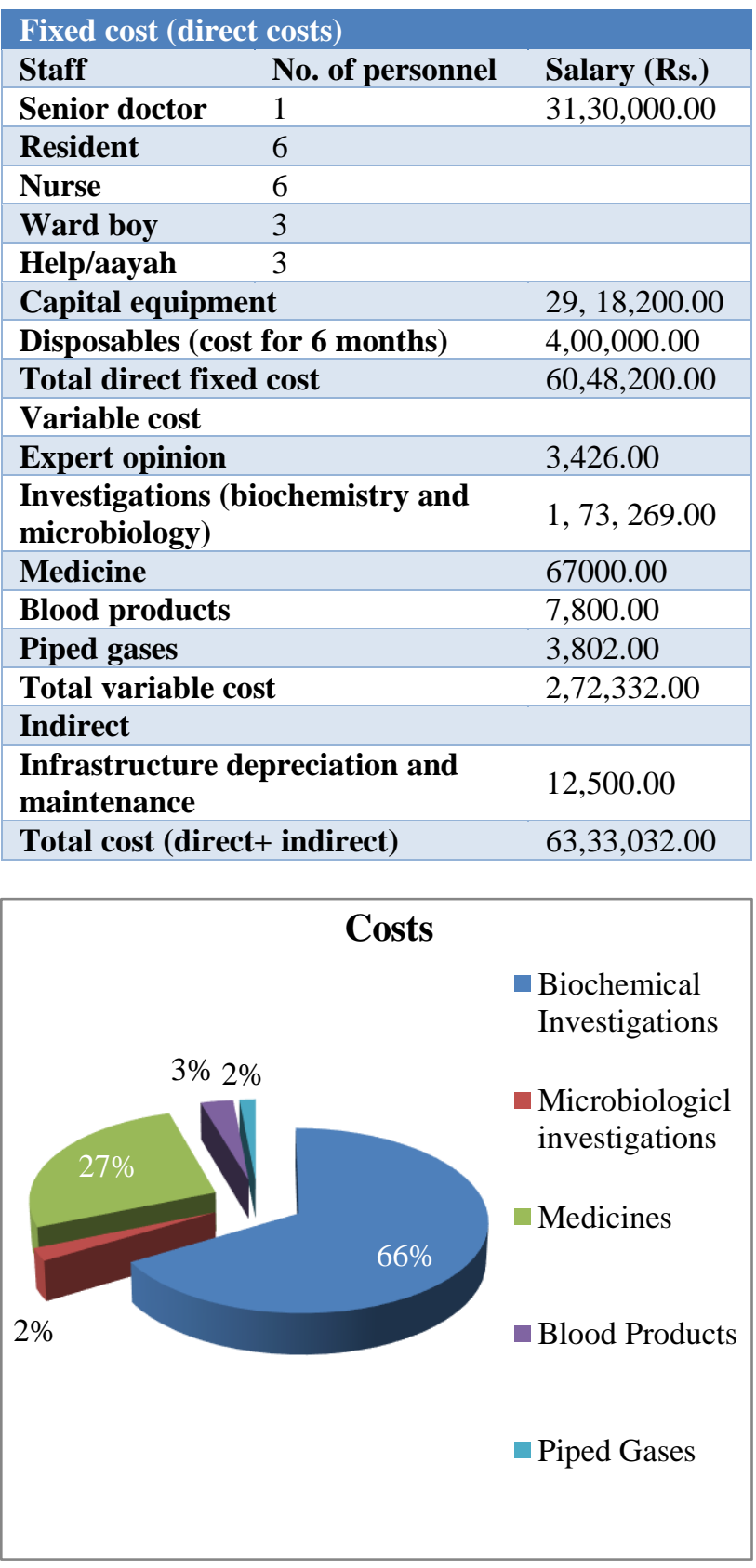

Figure 1: Distribution of direct variable costs.

An average of Rs. 260/patient/day (direct variable cost) was spent by the hospital for treatment of an infectious disease, Rs. 548.63/patient/day (direct variable cost) was spent by hospital for treatment of non-infectious disease/s and Rs. 487.82/patient/day was spent for treatment of pyrexia of unknown origin. While on the other hand the average cost paid by the patients was Rs. 169.96/patient/day for infectious disease, Rs. 356.21/patient/day for non-infectious disease and Rs. 320.90/patient/day for treatment of pyrexia of unknown origin. The major direct variable cost distributions were biochemical investigations [Rs. 1,67,518 (66\%)] and medicines [Rs. 67,000 (27\%)] (Figure 1). 60\% of the cost was spent by the hospital for treatment of infectious and pyrexia of unknown origin respectively, while in case of non-infectious diseases, $61 \%$ of the treatment cost was borne by the hospital.

The range of adjusted $\mathrm{R}$ square was calculated which ranged from 0.8309 to 0.9990 . The relationship was a linear one and hence, the cost of treatment of a patient that the hospital pays according to the diagnosis can be predicted by the number of bed days.

\section{DISCUSSION}

Though intensive care units (ICUs), only account for $10 \%$ of hospital beds, they consume nearly $22 \%$ of hospital resources. ${ }^{15}$ A diversity of costing methods has resulted in poor external validity and inability to compare findings between such evaluations. ${ }^{16}$ There is also considerable heterogeneity between countries and even within the country in allocation of resources and distribution of the services. ${ }^{17}$

There are very few Indian studies that have focussed on costing in an ICU setting. Also, intensive care services are provided free of cost in government hospitals that lack budgetary allocation or control.

To our knowledge, our study is one of the very few studies which were not limited to a particular clinical diagnosis; rather it was focussed in a unit wherein, diagnoses were multidisciplinary. The costs were divided into Direct and Indirect costs. The total direct fixed cost and direct variable cost of treatment of 167 pediatric patients admitted at the PICU over a time period of six months was calculated to be Rs. 64,48,200 and Rs. 2,72,332 respectively. The indirect cost was calculated to be Rs. 12,500. The average cost of treatment of infectious and non-infectious diagnoses per patient per day spent by the hospital to be Rs. 260 and Rs. 548.63, respectively as compared to Rs. 169.96 and Rs. 356.21 spent by the patients with an average $4 \pm 1.1$ bed days. The calculated costs were substantially lower when compared to a study conducted by Haque and Siddique et al at a PICU in a tertiary care hospital in Pakistan which calculated the average per patient per day cost to be Rs. 37,306. Similar cost analysis studies have been conducted at different intensive care settings. ${ }^{18}$ Karambelkar and Malwade et al conducted a study wherein, the mean treatment costs of neonates at a critical care setting at a private hospital in India was calculated to be Rs. 6,137 (US \$90.7) per patient per day. ${ }^{19}$ Another study calculated the average daily ICU cost to be Rs. 17,255 (US \$255). ${ }^{20}$ As per the study conducted by Kumar and Vishwanathan et al the total cost/bed/day for a multi-specialty ICU was Rs. $14,976.9 .^{21}$

Our study was not limited to a particular clinical diagnosis; rather it was focussed in a unit wherein, diagnoses were multidisciplinary. This approach is more practical and justifiable when we consider cost analysis studies to 
improve the allocation of resources and the overall infrastructure of a healthcare setting.

In our study we justified the consideration of both the diagnoses and the number of bed days in analysing costs of patient care at an intensive care unit setting, wherein, 83-99.99\% $(\mathrm{p}<0.05)$ of the total treatment costs depended on the diagnosis taking the no. of bed days of the patients. Also in a country like India $90 \%$ of the healthcare expenses are borne by the patient and almost $40 \%$ of the patients treated at private hospitals have to borrow money or sell assets. $^{22}$

\section{CONCLUSION}

It is essential for clinicians and administrators to comprehend the enormous resources and the consequent expenses that are involved in commissioning and running an intensive care unit. This study attempts to quantify in financial terms, the expenditure involved in running a paediatric ICU in a tertiary care hospital so as to assist doctors and healthcare decision makers in allocation of resource in a developing country like India.

The limitations of the study were the sample size as well as the number of beds at the intensive care unit. More studies are required to be conducted with a larger sample size and at a larger setting. This would be helpful towards building infrastructure and towards allocation of resources, public sector hospitals can be brought at par with the private ones, thereby, reducing the financial burden of the patients.

\section{ACKNOWLEDGEMENTS}

Authors would like to acknowledge the scientific inputs given by Dr. Santosh Taur and Dr. Sandeep Bavdekar for the study.

\section{Funding: No funding sources}

Conflict of interest: None declared

Ethical approval: The study was approved by the Institutional Ethics Committee

\section{REFERENCES}

1. Marten R, McIntyre D, Travassos C, Shishkin S, Longde W, Reddy S, Vega J. An assessment of progress towards universal health coverage in Brazil, Russia, India, China, and South Africa (BRICS). Lancet. 2014;384:2164-71.

2. Jacobs P, Noseworthy TW. National estimates of intensive care utilization and costs: Canada and the United States. Crit Care Med. 1990;18:1282-6.

3. Kramer AA, Higgins TL, Zimmerman JE. Comparing observed and predicted mortality among ICUs using different prognostic systems: Why do performance assessments differ? Crit Care Med. 2015;43:261-9.

4. Hart JT. The inverse care law. The Lancet. 1971;297:405-12.
5. Shelat PR, Kumbar SK. A retrospective analysis of direct medical cost and cost of drug therapy in hospitalized patients at private hospital in Western India. J Clin Diagn Res. 2015;9:9-12.

6. Noseworthy TW, Konopad E, Shustack A, Johnston R, Grace M. Cost accounting of adult intensive care: methods and human and capital inputs. Crit Care Med. 1996;24(7):1168-72.

7. Ganai S, Farooq AJ, Haroon R, Mohammed SM, Ahmed T. Study of In-Patient Costing at a Tertiary Care Teaching Hospital of North India. JMSCR. 2016;4(10):13223-31.

8. Siedel J, Whiting PC, Edborroke DL. The costs of intensive care. Continuing Education in Anaesthesia, Critical Care and Pain. 2006;6(4):160-3.

9. Luc M, Orgeas G. Outcome, functional autonomy, and quality of life of elderly patients with a long-term intensive care unit stay. Critical Care Med. 2000;28(10):3389-95.

10. Prinja S, Manchanda N, Mohan P, Gupta G, Sethy G, Sen A, van den Hombergh H, Kumar R. Cost of Neonatal Intensive Care delivered through district level public hospitals in India. Indian Pediatr. 2013;50(9):839-46.

11. Karambelkar G, Malwade S, Karambelkar R. Costanalysis of healthcare in a private-sector Neonatal Intensive Care Unit in India. Indian Pediatr. 2016;53(9):793-5.

12. Sodhi J, Satpathy S, Sharma DK, Lodha R, Kapil A, Wadhwa N, Gupta SK. Healthcare associated infections in Pediatric Intensive Care Unit of a tertiary care hospital in India: Hospital stay and extra costs. Indian J Med Res. 2016;143(4):502-6.

13. Hsu BS, Brazelton TB III. A comparison of costs between medical and surgical patients in an academic Pediatric Intensive Care Unit. WMJ. 2015;114(6):2369.

14. Publication 946. How to Depreciate Property. 2017. Available at: https://www.irs.gov/publications/p946. Accessed on 05 April 2019.

15. Halpern NA, Bettes L, Greenstein R. Federal and nationwide intensive care units and healthcare costs: 1986-1992. Crit Care Med. 1994;22:2001-7.

16. Joshipura MK, Shah HS, Patel PR, Divatia PA. Trauma care systems in India - An overview. Indian J Crit Care Med. 2004;7:93-7.

17. Riewpaiboon A, Malaroje S, Kongsawatt S. Effect of costing methods on unit cost of hospital medical services. Trop Med Int Health. 2007;12:554-63.

18. Haque A, Siddique NR. Cost of Care in a Paediatric Intensive Care Unit of a Tertiary Care Hospital of Pakistan. JPMA. 2015;65:651 .

19. Karambelkar G, Malwade S, Karambelkar R. Cost analysis of Healthcare in a Private sector Neonatal Intensive Care Unit in India. Indian Pediatr. 2016;53(9):793-5.

20. Peter JV, Thomas K, Jeyaseelan L. Cost of Intensive Care in India. Int $\mathbf{J}$ Technol Assess Health Care. 2016;32(4):241-5. 
21. Kumar P, Jithesh V, Gupta SK. Does a single specialty intensive care unit make better business sense than a multi-specialty intensive care unit? A costing study in a trauma center in India. Saudi J Anaesth. 2015;9:18994.

22. Ghosh S. Catastrophic payments and impoverishment due to out-of-pocket health spending. Econ Pol Wkly. 2011;19(25):63-70.
Cite this article as: Munshi RP, Dhiman A, Save SU. Cost analysis of critical patient care at a pediatric intensive care unit of a tertiary care public hospital in an urban metropolis of India. Int J Basic Clin Pharmacol 2021;10:834-9. 